\title{
The Effect of Complete Dentures on the Quality of Life of Edentulous Patients in the South Indian Population Based on Gender and Systemic Disease
}

Madhan K. Seenivasan ${ }^{1}$, Fathima Banu ${ }^{1}$, Athiban Inbarajan ${ }^{1}$, Parthasarathy Natarajan ${ }^{2}$, Shanmuganathan Natarajan ${ }^{1}$, V Anand Kumar ${ }^{2}$

1. Prosthodontics, Sri Ramachandra University, Chennai, IND 2. Prosthodontics, Faculty of Dental Sciences, Sri Ramachandra Institute of Higher Education and Research, Chennai, IND

$\square$ Corresponding author: Athiban Inbarajan, athiban_mds@rediffmail.com Disclosures can be found in Additional Information at the end of the article

\section{Abstract}

\section{Purpose}

Different socio-demographic variables, such as age, gender, and systemic disease, may affect satisfaction with complete dentures. Several studies have failed to show strong correlations either between patient satisfaction with their dentures and their quality or between denture satisfaction and the quality of the denture-supporting tissues. Hence, this study utilized a standardized questionnaire that included questions from domains such as mastication, appearance, speech, comfort, health, denture care, and social status. These questionnaires were used to determine the level of complete denture satisfaction along with socio-demographic variables such as age, gender, and systemic condition.

\section{Materials and method}

A total number of 128 completely edentulous patients aged between 40 and 50 years were selected. A standardized questionnaire, with 19 questions based on denture satisfaction level and masticatory capacity in the domains of functional limitation (FL), psychological discomfort (D1), psychological disability (D2), and social disability (D3), was administered. All the questions were recorded on a scale of 2, 1, 0 based on satisfied, moderately satisfied, and not satisfied, whereas hardly ever, occasionally, and very often were used for masticatory capacity. Questions on denture satisfaction were asked based on the post-treatment satisfaction with the new maxillary/mandibular complete dentures of the patients.

Received 05/30/2019

Review began 06/06/2019 Review ended 06/06/2019 Published 06/17/2019

\section{(C) Copyright 2019}

Seenivasan et al. This is an open access article distributed under the terms of the Creative Commons Attribution License CC-BY 3.0., which permits unrestricted use, distribution, and reproduction in any medium, provided the original author and source are credited.

\section{Results}

Based on gender, the distribution of samples was $46.09 \%$ for male patients and $53.91 \%$ for female patients among the 128 patients selected. Similarly, based on systemic diseases, $66.41 \%$ had the presence of systemic disease while $28.13 \%$ did not have any systemic disease. Around $5.47 \%$ of the sample did not have any medical records. The predominance of psychological satisfaction was more for female patients. Based on systemic disease, it was observed that patients with the presence of systemic disease (Pn) were more psychologically comfortable than those who did not have systemic disease. The predominance of functional satisfaction was not marked in both genders. Based on systemic disease, it was observed that patients with the presence of systemic disease (Pn) had less functional comfort on mastication than those who did not have a systemic disease. 


\section{Conclusion}

The acceptance of and satisfaction with complete denture treatment were comparatively higher in patients who had a systemic disease than in those with a non-systemic disease in terms of psychological and social comfort, whereas, in functionality, patients with a non-systemic disease had a higher satisfaction level.

Categories: Miscellaneous, Quality Improvement, Epidemiology/Public Health

Keywords: quality of life, psychological and social comfort, standardized questionnaire, functional limitation, patient adaptation, rehabilitation

\section{Introduction}

Improved quality of life (QoL), together with a decline in mortality rates, has led to the growth of the elderly population worldwide. Several studies have failed to show strong correlations between either patient satisfaction with their dentures and their quality or denture satisfaction and the quality of the denture-supporting tissues [1-3]. Despite a global decrease in the edentulous rate, with great numbers of people reaching an advanced age, the number of patients without teeth continues to be high [4-5]. In India, being a developing country and having a huge population, there is a lack of awareness and management of the edentulous state and the rehabilitation of edentulous patients with complete dentures [6].

Since they are rarely life-threatening, little attention has been paid to the psychosocial impacts of oral conditions. Moreover, many researchers used to ignore the effects of the oral cavity on general health status, however, the need for the consideration of the oral health-related quality of life (QoL) has been increasingly acknowledged over the last decades and many studies highlight the psychosocial impacts of oral conditions. Edentulism is a chronic disease so functional improvement is more important than cure. The patient's perception of the subjective experience of their denture is also important for dentists to motivate complete denture wearers, which is important for successful treatment.

Among the most important goals of dental care is helping patients in their attempts to reach an acceptable level of satisfaction with their oral cavity and dentition [7]. The literature contains many studies exploring the unique and vague relationship between psychological profiles and satisfaction with the dental status in many fields of dentistry [8]. Different socio-demographic variables, such as age, gender, and systemic disease, which may affect the satisfaction with complete dentures. Several studies have failed to show strong correlations between either patient satisfaction with their dentures and their quality or denture satisfaction and the quality of the denture-supporting tissues. Hence, this study utilized a standardized questionnaire that included questions from domains such as mastication, appearance, speech, comfort, health, denture care, and social status. These questionnaires were used to determine the level of complete denture satisfaction with socio-demographic variables such as age, gender, and systemic condition.

\section{Materials And Methods}

A total number of 128 completely edentulous patients who satisfied criteria, such as no past medical history, which affects the oral condition, new denture wearers, period of edentulousness varying between six months to one year, and a Class I completely edentulous state, as classified by the American College of Prosthodontics, were included in the study. Ethical clearance was obtained from the institution and subjects were voluntarily involved in the study. The subjects were in the age group of 40-50 years and grouped based on sex and on the presence or absence of systemic disease. Complete removable prostheses were fabricated 


\section{Cureus}

and their quality was assessed based on the method given by Sato et al. [9]. The patients were interviewed at two to three months post-treatment. A single interviewer had conducted all the interviews to minimize variability. A standardized questionnaire, with 19 questions based on denture satisfaction level and masticatory capacity in the domains of functional limitation (FL), psychological discomfort (D1), psychological disability (D2), and social disability (D3), was administered (Table 1). All the questions were recorded on a scale of 2, 1, 0 based on satisfied, moderately satisfied, and not satisfied, whereas hardly ever, occasionally, and very often were used for masticatory capacity. Questions on denture satisfaction were asked based on the post-treatment satisfaction with the new maxillary/mandibular complete dentures of the patients. Statistical analysis was done using Statistical Package for Sciences (version 21.0, IBM Corp., Armonk, NY, US). The significance of the percentage error of the two groups was tested by the student $t$-test and $p$-value denoted the level of significance $(p<.05)$. 


\section{Cureus}

\section{S.No Questionnaire}

SAQ 1 With respect to how comfortable your denture are, how satisfied are you

SAQ 2 With respect to being self-assured and self-conscious, how satisfied are you with your dentures

SAQ 3 Are you satisfied with your smile

SAQ 4 With respect to appearance, how satisfied are you

SAQ 5 with respect to your professional performance, how satisfied are you

SAQ 6 How do you feel pleasure you get from food, compared to your natural teeth

SAQ 7 With respect to chewing, how satisfied are you with your dentures

MCQ 1 In comparison with other people, do you perceive that you take longer to chew the foods during meals

MCQ 2 Have you been irritable when having meals with other people

MCQ 3 Do you feel uneasy during meals due to lack of denture security and instability

MCQ 4 have you been embarrassed when eating with other people in meals

MCQ 5 have you been totally unable to function because of problem with your denture

MCQ 6 Have you ever had to interrupt meals because of problem with your denture

MCQ 7 have you found it difficult to chew any foods because of problems with your denture

Do you need any special food preparation to enable e=chewing (such as cooking cutting into small parts? humidification)

MCQ 9 How stable is your denture when eating food of certain consistency

MCQ

10

Do you need force to swallow foods after chewing

MCQ

Do you think your swallowing larger pieces of food due to lack of proper fragmentation

$\mathrm{MCQ}$

12

Have you found it uncomfortable to chew any foods with dentures

\section{TABLE 1: Questionnaire for evaluating satisfaction level and masticatory ability}

SAQ - Satisfaction level questionnaire, MCQ - Masticatory ability questionnaire

\section{Results}

\section{Distribution of sample}

Based on gender, among the 128 selected patients, $46.09 \%$ were male patients and $53.91 \%$ were female. Similarly, based on systemic diseases, $66.41 \%$ among the selected patients had the presence of a systemic disease while $28.13 \%$ did not have any systemic disease and around 


\section{Cureus}

$5.47 \%$ of the patients did not have any medical records to know their medical conditions.

\section{Psychological discomfort}

On postoperative assessment, both male and female edentulous patients were well-satisfied with the prosthesis and were psychologically comfortable. Though there was no statistical difference between male ( $\mathrm{Mn}$ ) and female (Fn) patients, it was observed that the distribution of the sample was $\mathrm{Mn}=36$ and $\mathrm{Fn}=37$ for SAQ1, Mn = 37 and $\mathrm{Fn}=40$ for SAQ2, and $\mathrm{Mn}=47$ and $\mathrm{Fn}=52$ for SAQ3. The predominance of psychological satisfaction was more for female patients numerically. Based on systemic disease, it was observed that patients with the presence of a systemic disease $(\mathrm{Pn})$ were more psychologically comfortable than those who did not have any systemic disease $(\mathrm{An})$ with $\mathrm{Pn}=67$ and $\mathrm{An}=1$ for SAQ1, $\mathrm{Pn}=70$ and $\mathrm{An}=1$ for SAQ2, and $\mathrm{Pn}=$ 80 and $\mathrm{An}=10$ for SAQ (Table 2).

\begin{tabular}{|l|l|l|l|l|l|}
\hline Questionnaire & Gender & Satisfied & Moderately Satisfied & Not Satisfied & Pearson Chi-Square P-value \\
\hline SAQ4 & Male & 36 & 14 & 8 & \\
& Female & 37 & 18 & 14 & 0.54707 \\
SAQ5 & Male & 37 & 15 & 7 & \\
& Female & 40 & 14 & 15 & 0.31772 \\
SAQ9 & Male & 47 & 7 & 5 & 0.25879 \\
& Female & 52 & 5 & 12 & \\
MCQ9 & Male & 36 & 23 & 0 & 0.3721 \\
& Female & 38 & 29 & 2 & 0.00659 \\
MCQ12 & Male & 52 & 7 & 0 & 4 \\
\hline
\end{tabular}

\section{TABLE 2: Psycological discomfort based on gender}

$S A Q$ - Satisfaction level questionnaire, $M C Q$ - Masticatory ability questionnaire

Based on masticatory ability, both male and female edentulous patients had improved psychological comfort on mastication with the prosthesis. Though there was no statistical difference between male and female patients, it was observed that the distribution of the sample was $\mathrm{Mn}=36$ and $\mathrm{Fn}=38$ for MCQ1 and Mn = 52 and Fn =45 for MCQ2. It was also found that the predominance of psychological satisfaction was more for female patients numerically. Based on systemic disease, it was observed that patients with the presence of a systemic disease (Pn) were more satisfied with masticatory ability than those who did not have any systemic disease (An) with Pn = 67 and An = 1 for MCQ1, Pn = 85 and An = 1 for MCQ2 (Table 3). 


\section{Cureus}

\begin{tabular}{|c|c|c|c|c|c|}
\hline Questionnaire & $\begin{array}{l}\text { Systemic } \\
\text { Disease }\end{array}$ & Satisfied & Moderately Satisfied & Not Satisfied & Pearson Chi-Square P value \\
\hline \multirow{3}{*}{ SAQ 4} & No record & 1 & 1 & 1 & \multirow{3}{*}{0.59798} \\
\hline & Present & 67 & 0 & 18 & \\
\hline & Absent & 1 & 27 & 1 & \\
\hline \multirow{3}{*}{ SAQ 5} & No record & 1 & 1 & 1 & \multirow{3}{*}{0.57793} \\
\hline & Present & 70 & 1 & 5 & \\
\hline & Absent & 1 & 20 & 16 & \\
\hline \multirow{3}{*}{ SAQ 9} & No record & 2 & 0 & 1 & \multirow{3}{*}{0.40062} \\
\hline & Present & 80 & 0 & 1 & \\
\hline & Absent & 10 & 10 & 13 & \\
\hline \multirow{3}{*}{ MCQ 9} & No record & 2 & 1 & 0 & \multirow{3}{*}{0.99377} \\
\hline & Present & 67 & 1 & 2 & \\
\hline & Absent & 1 & 44 & 0 & \\
\hline \multirow{3}{*}{ MCQ 12} & No record & 3 & 0 & 0 & \multirow{3}{*}{0.73416} \\
\hline & Present & 85 & 1 & 0 & \\
\hline & ADsent & 1 & 24 & 4 & \\
\hline
\end{tabular}

\section{TABLE 3: Psycological discomfort based on systemic diseases}

SAQ - Satisfaction level questionnaire, MCQ - Masticatory ability questionnaire

\section{Social disability}

On postoperative assessment, both male and female edentulous patients were well-satisfied with their social ability after wearing the prosthesis. Though there was no statistical difference between male and female patients, it was observed that the distribution of samples was $\mathrm{Mn}=$ 45 and $\mathrm{Fn}=41$ for SAQ 4 and $\mathrm{Mn}=42$ and $\mathrm{Fn}=44$ for SAQ5. The predominance of psychological satisfaction was not well-marked in both genders. Based on systemic disease, it was observed that patients with the presence of systemic disease (Pn) were more socially comfortable than those who did not have systemic disease (An), with $\mathrm{Pn}=35$ and $\mathrm{An}=38$ for SAQ4 and $\mathrm{Pn}=78$ and An = 1 for SAQ4 (Table 4). 


\section{Cureus}

\begin{tabular}{|c|c|c|c|c|c|}
\hline Questionnaire & Gender & Satisfied & Moderately Satisfied & Not Satisfied & Pearson Chi-Square P-value \\
\hline \multirow{2}{*}{ SAQ3 } & Male & 45 & 8 & 6 & \multirow{2}{*}{0.12622} \\
\hline & Female & 41 & 15 & 13 & \\
\hline \multirow{2}{*}{ SAQ7 } & Male & 42 & 9 & 8 & \multirow{2}{*}{0.66002} \\
\hline & Female & 44 & 14 & 11 & \\
\hline \multirow{2}{*}{ MCQ10 } & Male & 40 & 19 & 0 & \multirow{2}{*}{0.29288} \\
\hline & Female & 50 & 17 & 2 & \\
\hline \multirow{2}{*}{ MCQ11 } & Male & 50 & 9 & 0 & \multirow{2}{*}{0.05624} \\
\hline & Female & 48 & 17 & 4 & \\
\hline \multirow{2}{*}{ MCQ13 } & Male & 46 & 12 & 1 & \multirow{2}{*}{0.4096} \\
\hline & Female & 48 & 16 & 4 & \\
\hline
\end{tabular}

\section{TABLE 4: Social disability based on gender}

SAQ - Satisfaction level questionnaire, MCQ - Masticatory ability questionnaire

Based on masticatory ability, both male and female edentulous patients had improved social ability on mastication with a prosthesis. Though there was no statistical difference between male and female patients, it was observed that the distribution of samples was $\mathrm{Mn}=40$ and Fn = 50 for MCQ3, Mn = 50 and Fn =48 for MCQ4, and Mn = 46 and Fn = 48 for MCQ5. Based on systemic disease, it was observed that patients with the presence of systemic disease (Pn) had more masticatory ability based on social ability than those who did not have systemic disease (An) with $\mathrm{Pn}=80$ and $\mathrm{An}=1$ for MCQ3, $\mathrm{Pn}=85$ and $\mathrm{An}=1$ for MCQ4, and $\mathrm{Pn}=86$ and $\mathrm{An}=1$ for MCQ5 (Table 5). 


\section{Cureus}

\begin{tabular}{|c|c|c|c|c|c|}
\hline Questionnaire & $\begin{array}{l}\text { Systemic } \\
\text { Disease }\end{array}$ & Satisfied & Moderately Satisfied & Not Satisfied & Pearson Chi-Square $P$ value \\
\hline \multirow{3}{*}{ SAQ 3} & No record & 1 & 1 & 1 & \multirow{3}{*}{0.46574} \\
\hline & Present & 78 & 0 & 1 & \\
\hline & Absent & 1 & 17 & 18 & \\
\hline \multirow{3}{*}{ SAQ 7} & No record & 1 & 0 & 2 & \multirow{3}{*}{0.09377} \\
\hline & Present & 78 & 2 & 1 & \\
\hline & Absent & 1 & 19 & 16 & \\
\hline \multirow{3}{*}{ MCQ 10} & No record & 2 & 1 & 0 & \multirow{3}{*}{0.96253} \\
\hline & Present & 80 & 31 & 2 & \\
\hline & Absent & 1 & 1 & 0 & \\
\hline \multirow{3}{*}{ MCQ 11} & No record & 2 & 1 & 0 & \multirow{3}{*}{0.71968} \\
\hline & Present & 90 & 19 & 4 & \\
\hline & Absent & 1 & 1 & 0 & \\
\hline \multirow{3}{*}{ MCQ 13} & No record & 3 & 0 & 0 & \multirow{3}{*}{0.69554} \\
\hline & Present & 86 & 21 & 5 & \\
\hline & Absent & 1 & 1 & 0 & \\
\hline
\end{tabular}

\section{TABLE 5: Social disability based on systemic diseases}

\section{Functional limitation}

On postoperative assessment, both male and female edentulous patients were functionally well-satisfied on wearing the prosthesis. Though there was no statistical difference between male and female patients, it was observed that the distribution of samples was $\mathrm{Mn}=35$ and Fn $=38$ for SAQ6 and $\mathrm{Mn}=40$ and $\mathrm{Fn}=35$ for SAQ7. The predominance of functional satisfaction was not well-marked in both genders. Based on systemic disease, it was observed that patients with the presence of systemic disease (Pn) had less functional comfort on mastication than those who did not have systemic disease (An), with $\mathrm{Pn}=13$ and $\mathrm{An}=55$ for SAQ6 and $\mathrm{Pn}=14$ and $\mathrm{An}=56$ for SAQ7 (Table 6).

\begin{tabular}{|c|c|c|c|c|c|}
\hline Questionnaire & $\begin{array}{l}\text { Systemic } \\
\text { Disease }\end{array}$ & Satisfied & Moderately Satisfied & Not Satisfied & Pearson Chi-Square $\mathbf{P}$ value \\
\hline & No record & 1 & 0 & 1 & \\
\hline
\end{tabular}




\section{Cureus}

\begin{tabular}{|c|c|c|c|c|c|}
\hline \multirow[t]{2}{*}{ SAQ 1} & Present & 13 & 5 & 5 & \multirow[t]{2}{*}{0.98279} \\
\hline & Absent & 55 & 19 & 21 & \\
\hline \multirow{3}{*}{ SAQ 2} & No record & 1 & 0 & 1 & \multirow{3}{*}{0.93491} \\
\hline & Present & 14 & 5 & 4 & \\
\hline & Absent & 56 & 24 & 15 & \\
\hline \multirow{3}{*}{ MCQ1 } & No record & 1 & 1 & 0 & \multirow{3}{*}{0.90129} \\
\hline & Present & 17 & 6 & 1 & \\
\hline & Absent & 69 & 26 & 2 & \\
\hline \multirow{3}{*}{ MCQ 2} & No record & 0 & 1 & 1 & \multirow{3}{*}{0.81405} \\
\hline & Present & 13 & 9 & 1 & \\
\hline & Absent & 57 & 36 & 2 & \\
\hline \multirow{3}{*}{ MCQ 3} & No record & 1 & 1 & 1 & \multirow{3}{*}{0.39844} \\
\hline & Present & 18 & 4 & 1 & \\
\hline & Absent & 61 & 30 & 4 & \\
\hline \multirow{3}{*}{ MCQ 4} & No record & 1 & 1 & 1 & \multirow{3}{*}{0.52638} \\
\hline & Present & 16 & 7 & 0 & \\
\hline & Absent & 58 & 33 & 4 & \\
\hline \multirow{3}{*}{ MCQ 5} & No record & 1 & 1 & 1 & \multirow{3}{*}{0.68488} \\
\hline & Present & 17 & 6 & 0 & \\
\hline & Absent & 69 & 23 & 3 & \\
\hline \multirow{3}{*}{ MCQ 6} & No record & 1 & 1 & 1 & \multirow{3}{*}{0.80203} \\
\hline & Present & 15 & 7 & 1 & \\
\hline & Absent & 66 & 27 & 2 & \\
\hline \multirow{3}{*}{ MCQ 7} & No record & 1 & 1 & 1 & \multirow{3}{*}{0.65814} \\
\hline & Present & 15 & 8 & 0 & \\
\hline & Absent & 63 & 29 & 3 & \\
\hline
\end{tabular}

\section{TABLE 6: Functional limitation based on systemic disease}

$S A Q$ - Satisfaction level questionnaire, $M C Q$ - Masticatory ability questionnaire 


\section{Cureus}

functional ability on mastication with a prosthesis. Though there was no statistical difference between male and female patients, it was observed that the distribution of samples was $\mathrm{Mn}=$ 45 and $\mathrm{Fn}=43$ for MCQ6, $\mathrm{Mn}=35$ and $\mathrm{Fn}=38$ for MCQ7, $\mathrm{Mn}=41$ and $\mathrm{Fn}=42$ for MCQ8, $\mathrm{Mn}=$ 37 and Fn $=41$ for MCQ9, $\mathrm{Mn}=43$ and Fn $=49$ for MCQ10, Mn = 40 and Fn $=47$ for MCQ11, and $\mathrm{Mn}=40$ and $\mathrm{Fn}=42$ for MCQ12. Based on systemic disease, it was observed that patients with the presence of systemic disease (Pn) had less masticatory ability based on function than those who did not have systemic disease (An), with $\mathrm{Mn}=17$ and $\mathrm{Fn}=69$ for MCQ6, $\mathrm{Mn}=13$ and Fn = 57 for MCQ7, Mn = 18 and Fn = 61 for MCQ8, Mn = 16 and Fn = 58 for MCQ9, Mn = 17 and Fn = 69 for MCQ10, Mn = 15 and Fn = 66 for MCQ11, and Mn = 15 and Fn = 63 for MCQ12 (Table 7).

\begin{tabular}{|c|c|c|c|c|c|}
\hline Questionnaire & Gender & Satisfied & Moderately Satisfied & Not Satisfied & Pearson Chi-Square P-value \\
\hline \multirow{2}{*}{ SAQ1 } & Male & 35 & 13 & 11 & \multirow{2}{*}{0.71574} \\
\hline & Female & 38 & 14 & 17 & \\
\hline \multirow{2}{*}{ SAQ2 } & Male & 40 & 12 & 7 & \multirow{2}{*}{0.14162} \\
\hline & Female & 35 & 20 & 14 & \\
\hline \multirow{2}{*}{ MCQ1 } & Male & 45 & 14 & 0 & \multirow{2}{*}{0.08959} \\
\hline & Female & 43 & 26 & 1 & \\
\hline \multirow{2}{*}{ MCQ2 } & Male & 35 & 24 & 0 & \multirow{2}{*}{0.26369} \\
\hline & Female & 38 & 28 & 3 & \\
\hline \multirow{2}{*}{ MCQ3 } & Male & 41 & 16 & 2 & \multirow{2}{*}{0.59538} \\
\hline & Female & 42 & 24 & 3 & \\
\hline \multirow{2}{*}{ MCQ4 } & Male & 37 & 21 & 1 & \multirow{2}{*}{0.67826} \\
\hline & Female & 41 & 25 & 3 & \\
\hline \multirow{2}{*}{ MCQ5 } & Male & 43 & 15 & 1 & \multirow{2}{*}{0.89698} \\
\hline & Female & 49 & 18 & 2 & \\
\hline \multirow{2}{*}{ MCQ6 } & Male & 40 & 19 & 0 & \multirow{2}{*}{0.24671} \\
\hline & Female & 47 & 19 & 3 & \\
\hline \multirow{2}{*}{ MCQ7 } & Male & 40 & 19 & 0 & \multirow{2}{*}{0.23854} \\
\hline & Female & 42 & 24 & 3 & \\
\hline
\end{tabular}

\section{TABLE 7: Functional limitation based on gender}

$S A Q$ - Satisfaction level questionnaire, MCQ - Masticatory ability questionnaire

\section{Discussion}

Feine et al. reported that patient satisfaction with therapy is likely to be the distinguishing 
outcome of many treatments for chronic diseases for which living with treatment is a more realistic objective than cure [10].

Females with fitted, conventional, complete dentures reported less satisfaction with aesthetics and ability to chew than males [11]. Nevertheless, some studies reported no significant relationship between gender and satisfaction with complete denture treatment [12-15]. However, others found that males were more satisfied with dentures [16]. However, not all complete denture wearers are able to adapt to their dentures, even if the dentures fulfilled all conventional prosthodontic criteria.

Our findings concerning the qualities of stability, retention, occlusion, articulation, and vertical dimension of the complete dentures, together with the observation that these features become impaired with the increasing age of the dentures, support the findings of Hoad-Reddick (1989) [17].

A comparison of these features with the age of the dentures caused some problems, however, because a number of the elderly people had difficulty in recalling the history of their dental treatment. Of course, this may result from their advanced age and/or the prevalence of mild dementia diagnosed in the medical examination of these subjects, which ranged from $5 \%$ in the youngest age group to $27 \%$ in the oldest (Juva et al., 1993) [18].

The degree of satisfaction based on each of these elements for 120 patients (both males and females) were separately averaged, as presented in Table 2. Moreover, the degree of satisfaction based on the individual elements was found to impart no significant difference apart from that based on the function criterion where the males' degree of satisfaction was $86.36 \%$ while that of females was $65.8 \%$. This may be due to the male patients generally giving more important to function, whereas for the female patients, aesthetics was a main concern.

Patient adaptation to the reestablishment varies as adaptation depends on neuromuscular control, but we were able to see that three months was sufficient for the majority of patients to achieve improvement in these symptoms. Several factors can influence satisfaction. They are interrelated and frequently have an associated effect. They include not only factors exclusive to the dental prosthesis, such as comfort, ability to masticate, aesthetics, and retention but the systemic health or general health of the patient also had an effect on adaptation.

Some of the systemic diseases that adversely affect patient's satisfaction with their dentures include hyposalivation, Parkinson's disease, myasthenia gravis, bulbar palsy, and diseases with either a strong connection to emotional stress or impairing mental health [19-20]. The ability to adapt to new dentures and the prognosis will generally diminish in proportion to the health status.

The effect of gender variation on patient's satisfaction with their dentures has also been examined. It was found that men were generally more satisfied with their dentures when compared to women except when it came to aesthetics, where women scored higher. In this study, the treatment of rehabilitated patients with a total loss of teeth was analyzed in terms of patient QoL by administering the OHIP-EDENT (a specific questionnaire for edentulous patients (EDENT) based on the OHIP) before and three months after rehabilitation with a new complete denture.

\section{Conclusions}

The acceptance and satisfaction of complete denture treatment were comparatively higher in patients with systemic disease than in patients with non-systemic disease in terms of 
psychological comfort. Female patients are more psychologically satisfied as compared to male patients.

In terms of social disability, patients with systemic disease are more socially comfortable than patients with a non-systemic disease. Again, females are more socially comfortable.

Based on functionality, patients with a non-systemic disease have a higher complete denture treatment satisfaction level and higher masticatory ability as compared with non-systemic disease patients.

\section{Additional Information}

\section{Disclosures}

Human subjects: Consent was obtained by all participants in this study. Animal subjects: All authors have confirmed that this study did not involve animal subjects or tissue. Conflicts of interest: In compliance with the ICMJE uniform disclosure form, all authors declare the following: Payment/services info: All authors have declared that no financial support was received from any organization for the submitted work. Financial relationships: All authors have declared that they have no financial relationships at present or within the previous three years with any organizations that might have an interest in the submitted work. Other relationships: All authors have declared that there are no other relationships or activities that could appear to have influenced the submitted work.

\section{References}

1. Garrett NR, Kapur KK, Perez P: Effects of improvements of poorly fitting dentures and new dentures on patient satisfaction. J Prosthet Dent. 1996, 76:403-413. 10.1016/S00223913(96)90546-6

2. Heydecke G, Klemetti E, Awad MA, Lund JP, Feine JS: Relationship between prosthodontic evaluation and patient ratings of mandibular conventional and implant prostheses. Int J Prosthodont. 2003, 16:307-312.

3. Carlsson GE: Critical review of some dogmas in prosthodontics . J Prosthodont Res. 2009, 53:3-10. 10.1016/j.jpor.2008.08.003

4. He W, Sengupta M, Velkoff VA, DeBarros KA: $65+$ in the United States . Current Population Reports. 2005, 2:23-209.

5. Slade GD, Spencer AJ: Development and evaluation of the oral health impact profile . Community Dent Health. 1994, 11:3-11.

6. Singh BP, Pradhan KN, Tripathi A, Tua R, Tripathi S: Effect of sociodemographic variables on complete denture satisfaction. J Adv Prosthodont. 2012, 4:43-51. 10.4047/jap.2012.4.1.43

7. Steele JG, Ayatollahi SM, Walls AW, Murray JJ: Clinical factors related to reported satisfaction with oral function amongst dentate older adults in England. Community Dent Oral Epidemiol. 1997, 25:143-149.

8. Cushing AM, Sheiham A, Maizels J: Developing socio-dental indicators-the social impact of dental disease. Community Dent Health. 1986, 3:3-17.

9. Sato Y, Hamada S, Akagawa Y, Tsuga K: A method of quantifying overall satisfaction of complete denture patients. J Oral Rehabil. 2000, 27:952-957.

10. Feine JS, Carlsson GE, Awad MA, et al.: The McGill consensus statement on overdentures. Mandibular two-implant overdentures as first choice standard of care for edentulous patients. Gerodontology. 2002, 19:3-4.

11. Lowental U, Tau S: Effects of ethnic origin, age and bereavement on complete denture patients. J Prosthet Dent. 1980, 44:133-136.

12. Weinstein M, Schuchman J, Lieberman J, Rosen P: Age and denture experience as determinants in patient denture satisfaction. J Prosthet Dent. 1988, 59:327-329.

13. Beck CB, Bates JF, Basker RM, Gutteridge DL, Harrison A: A survey of the dissatisfied denture patient. Eur J Prosthodont Restor Dent. 1993, 2:73-78. 


\section{Cureus}

14. Brunello DL, Mandikos MN: Construction faults, age, gender, and relative medical health: factors associated with complaints in complete denture patients. J Prosthet Dent. 1998, 79:545-554.

15. Al Quran F, Clifford T, Cooper C, Lamey PJ: Influence of psychological factors on the acceptance of complete dentures. Gerodontology. 2001, 18:135-140. 10.1111/j.17412358.2001.00035.x

16. Silverman S, Silverman SI, Silverman B, Garfinkel L: Self image and its relation to denture acceptance. J Prosthet Dent. 1976, 35:131-141.

17. Hoad-Reddick G: Oral pathology and prostheses--are they related? Investigations in an elderly population. J Oral Rehabil. 1989, 16:75-87.

18. Juva K, Sulkava R, Erkinjuntt T, Valvanne J, Tilvis R: Prevalence of dementia in the city of Helsinki. Acta Neurologica Scandinavica. 1993, 87:106-110. 10.1111/j.16000404.1993.tb04086.x

19. Basker RM, Davenport JC, Tomlin HR: Prosthetic Treatment of the Edentulous Patient. Wiley, US; 1992.

20. Weinstein M, Schuchman J, Lieberman J, Rosen P: Age and denture experience as determinants in patient denture satisfaction. J Prosthet Dent. 1988, 59:327-329. 